\title{
The nature of the activity deficit produced by inescapable shock
}

\author{
ROBERT C. DRUGAN and STEVEN F. MAIER \\ University of Colorado, Boulder, Colorado
}

\begin{abstract}
Two experiments investigated the nature and etiology of the reduced activity in the presence of shock produced by prior exposure to inescapable shock. Previous experiments have demonstrated this deficit in the presence of gridshock. However, gridshock hurts less if movement across the grids is reduced. It is thus unclear whether the inescapable-shock-produced deficit represents a facilitation of learning to reduce movement across the grids in order to alleviate pain or is an "unconditioned" reduction in movement in response to shock. The first experiment tested these possibilities by examining the effects of inescapable shock on subsequent movement during shock delivered via fixed tail electrodes to freely moving subjects. Inescapably shocked subjects still moved less in response to shock than did escapably shocked and restrained control subjects. Experiment 2 examined the possibility that this deficit occurs because unconditioned movement in response to shock during pretreatment diminishes after a few seconds, the reduction then being adventitiously reinforced by shortly ensuing shock termination. Activity during inescapable shock was closely monitored by ultrasonic motion detection. Although activity did decrease across trial blocks, the required within-trial patterns did not occur. Shockelicited activity did not diminish after a few seconds of shock, but remained unchanged across the 5-sec shock presentations.
\end{abstract}

Exposure to inescapable shock results in reduced activity in the presence of subsequent shocks (Anisman, DeCantanzaro, \& Remington, 1978; Jackson, Maier, \& Rapaport, 1978). There are a variety of explanations for such an activity deficit. Some (Anderson, Crowell, Cunningham, \& Lupo, 1979; Bracewell \& Black, 1974; Glazer \& Weiss, 1976a, 1976b; Levis, 1976) have argued that inactivity is acquired as a learned motor response to shock during pretreatment with inescapable shock, and transfers to the test situation because shock is again present. This transferred inactivity reaction then simply competes with the movement elicited by shock. Others have argued that inescapable shock depletes neurochemical systems necessary for the maintenance of movement (Weiss, Glazer, \& Pohorecky, 1976). When later exposed to shock, there is either not enough of the relevant substance present, or it is rapidly redepleted by the shock. Alternatively, it has been argued that exposure to inescapable shock leads to learning that shock cannot be controlled, such learning producing subsequent associative interference and reduced in-

This research was conducted in partial fulfillment of the requirements for the degree of Master of Arts in Psychology (R.C.D.). It was supported by NSF Grant BNS 78-00508 to S.F.M. The authors wish to express their appreciation to D. R. Thomas, J. W. Rudy, and D. A. Chiszar for their helpful suggestions. We thank Mary Lou Brown for assistance in preparation of the manuscript. Address all correspondence to Robert C. Drugan, Department of Psychology, Campus Box 345, University of Colorado, Boulder, Colorado 80309. centive to escape (e.g., Maier \& Seligman, 1976). This reduced incentive would be expected to result in diminished movement in the presence of shock. Finally, it has been shown that exposure to inescapable shock produces a change in sensitivity/reactivity to shock (Drugan, Maier, \& Misanin, Note 1) and an analgesic reaction to radiant heat $24 \mathrm{~h}$ later upon reexposure to shock (Jackson, Maier, \& Coon, 1979). Thus, inactivity in the presence of shock could result from such decreases in pain responsiveness (Maier \& Jackson, 1979).

These hypotheses have in common the assertion that the activity reduction is an "unconditioned" effect in the sense that it represents a carry-over from changes produced during exposure to inescapable shock rather than an effect produced by new learning during the test shocks. By "unconditioned" here, we do not mean that associative processes are not involved in the original determining processes in the inescapable shock phase, or that associative transfer is not involved. Rather, we mean only that the basis of the deficit is not something new learned during testing. However, both the Anisman et al. (1978) and the Jackson et al. (1978) studies, which documented the inescapable-shock-produced reduction in locomotion, examined activity during fixed-duration gridshocks. Unfortunately, it is easy for subjects to modify the severity of gridshocks. In particular, gridshock ought to be less painful if the rat reduces movement. There are two reasons. First, making and breaking contact with electrified grids is more aversive 
than continued contact (Muenzinger \& Waltz, 1932). Second, the aversiveness of shock correlates best with the power dissipated by the subject (Campbell \& Teghtsoonian, 1958) or with current density (Mowrer \& Miller, 1942), and both vary inversely with the number of paws grounded (Wilson \& Butcher, 1980). In fact, Wilson and Butcher (1980), using a subcutaneous back electrode, found that the threshold current required to produce vocalization increased as the number of paws grounded increased. Thus, shock hurts less if all 4 paws are grounded, a condition more likely to be met when the subject is not moving across the grids. That is, all four paws are unlikely to be on the grids simultaneously while the animal is in motion. Subjects could learn such contingencies with continued exposure to fixed-duration inescapable gridshocks, thereby resulting in a reduction in activity learned during the testing session. Thus, inescapable shock could have produced an activity deficit in the Anisman et al. (1978) and Jackson et al. (1978) experiments because it facilitated the learning of these contingencies rather than because it produced an unconditioned activity reduction resembling the types described above. In fact, Wilson and Butcher (1980) suggested that many of the effects of inescapable shock might be dependent on this contingency between aversiveness and movement typically presented during testing.

It is not implausible that inescapably shocked animals are later less active in the presence of shock because they learn more rapidly that gridshock is less painful if movement is inhibited. Some investigators have found inescapable shock to facilitate punishment or passive avoidance learning (Hollis \& Overmier, 1973; Kurtz \& Walters, 1962). That is, inescapably shocked subjects in these experiments more rapidly reduced the performance of responses that led to shock than did controls (however, for a counterinstance, see Jackson et al., 1978). This sort of effect could produce more rapid learning that shock hurts more if movement increases. Moreover, if animals do learn to be inactive during inescapable shock because either adventitious or real contingencies exist, the presence of a real contingency between movement and aversiveness during testing should perpetuate the transferred inactivity. This argument suggests the examination of activity in the presence of shocks which are not so readily modified by movement. The obvious choice is fixed shock delivered by electrodes fastened to the tail of the subject. Here, electrical contact with the power source cannot be modified by movement. The only further requirement is that free movement not be severely restricted by the electrodes.

\section{EXPERIMENT 1}

Berk, Marlin, and Miller (1977) have developed a procedure for delivering shock to freely moving rats via electrodes attached to the tail. The purpose of Experiment 1 was to determine whether inescapable shock produces a reduction in the movement elicited by such "unmodifiable" shock. Rats were given either escapable shock, yoked-inescapable shock, or no shock under conditions known to produce behavioral learned helplessness, as assessed by shuttlebox escape behavior (Maier \& Jackson, 1979). Then, 24 h later, they were tested for activity in the presence of fixedduration tailshock.

\section{Method}

Subjects. Twenty-four naive male albino rats, obtained from the Holtzman suppliers, Madison, Wisconsin, and 330-350 $\mathrm{g}$ at the time of testing, served as subjects. They were individually housed and maintained on a 12-h light-dark cycle. Food and water was provided ad lib throughout.

Apparatus. Escape-yoke wheel-turn boxes $(15.5 \times 12.0 \times$ $17.0 \mathrm{~cm}$ ) modeled after those used by Weiss, Stone, and Harrell (1970) were used for the pretreatment phase. The side and front walls were made of clear Plexiglas; the rear walls and floor were made of Masonite. A grooved Plexiglas wheel extended $1.7 \mathrm{~cm}$ into the front of the chamber, through a hole $8.0 \mathrm{~cm}$ from the floor of the box. The wheel required a force of about $.50 \mathrm{~N}$ to turn. The rat's tail was extended through a slot in the rear wall of the chamber and was taped to a Plexiglas rod parallel to the floor of the chamber. Shock was applied through electrodes attached to the rat's tail and augmented with electrode paste. The shock sources were modeled after the Grason-Stadler Model 700. The apparatus used to test activity in the testing phase was modeled after that described by Berk et al. (1977). It consisted of a $43 \times$ $43 \mathrm{~cm}$ square Plexiglas open-field chamber with a Plexiglas floor. A hinged ceiling, with a slot (about $2.54 \mathrm{~cm}$ wide) running from the front to the back of the apparatus, was $11.4 \mathrm{~cm}$ above the floor. An ultrasonic motion transmitter and receiver were mounted $12.7 \mathrm{~cm}$ apart on the side of the open-field apparatus $5.08 \mathrm{~cm}$ above the floor. The motion detector operates in a sonar-like fashion by detecting variations in air vibrations. The sensitivity of the detector was set so that a pendulum (O'Connell, Chiszar, \& Smith, 1981) placed $7.54 \mathrm{~cm}$ in front of the sensors registered an average of eight activity counts (plus or minus one) for a full swing cycle. The pendulum object was a plastic disk, $10 \mathrm{~cm}$ in diameter, mounted on a cam driven by an electric motor. The disk swept through an arc of $15 \mathrm{~cm}$ at a rate of $30 \mathrm{rpm}$. This sensitivity setting detects body movements as small as head turning and scratching.

Procedure. The experimental procedure consisted of two phases. The pretreatment phase (helplessness training) employed the standard triadic design (escapable shock, yoked-inescapable shock, and nonshock controls). The first group (escape) received escape training in the wheel-turn boxes. The escape session was identical to that used in previous studies and consisted of 80 unsignaled shock trials presented on a variable time schedule, with a mean intertrial interval of $60 \mathrm{sec}$ (range, $30-120 \mathrm{sec}$ ). Shock could be terminated by turning the wheel one-half of a complete rotation after the first $.8 \mathrm{sec}$ of the trial had elapsed. Responses within $.8 \mathrm{sec}$ of shock onset had no consequence. The shock terminated automatically if the subject had not responded after $30 \mathrm{sec}$ of shock. Shock intensity was initially set at $.8 \mathrm{~mA}$ and was incremented to $1.0 \mathrm{~mA}$ after 20 trials, to $1.3 \mathrm{~mA}$ after 40 trials, and to $1.6 \mathrm{~mA}$ after 60 trials. This was done because responding in this situation deteriorates with a constant shock intensity. The subjects in the second group (yoked) were each paired with a member of the escape group and received the same shocks as did their yoked partners in the escape group. Wheel turning had no effect on shock duration for this group. The members of the third group of rats (restrained) were merely restrained in the wheel-turn boxes for a period of time equal to that spent in the boxes by the other two groups. 
Twenty-four hours following the pretreatment phase, the three groups were tested for activity during shock in the open-field apparatus. The shock was administered via fixed tail electrodes. The rat's tail was pulled up through the slot in the ceiling, and electrodes were taped to the caudal portion of the subject's tail. The rat's tail was prevented from being pulled back into the chamber by placing a Plexiglas disk (with a hole in the center) over the rat's tail rostral to the electrodes and then wrapping a cord of adhesive tape just caudal to the disk. The disk was able to slide freely on top of the ceiling, thus enabling relatively uninhibited movement by the subject. Activity in the open-field was measured by the ultrasonic motion detector.

The schedule for the test session consisted of a 5-min adaptation period followed by 24 trials of 30 -sec continuous tailshock (.6 mA). Each trial was separated by a 1 min intertrial interval.

\section{Results and Discussion}

All subjects in the escape group learned to escape shock. For each subject, wheel-turn latencies were shorter in the last block of 10 trials than in the first block. There was no overlap in these latencies. The data from Experiment 1 are shown in Figure 1, which presents mean total activity counts across blocks of 8 trials.

As can be seen in Figure 1, the yoked inescapably shocked subjects were considerably less active in the presence of shock than were the escapably shocked and nonshocked controls throughout all three trial blocks. In addition, all groups showed decreased activity across trial blocks. These observations were statistically confirmed by a repeated measures analysis of variance. The ANOVA revealed significant group $[F(2,21)=3.53, p<.05]$ and trials $[F(2,42)$ $=66.40, p<.001]$ effects. However, the group $\times$ trial blocks interaction was not significant $[F(4,42)$ $<1.01$. Subsequent Newman-Keuls comparisons $(\alpha=.05)$ revealed that the escape and restrained groups were significantly more active than the yoked group. Also, the escape and restrained groups did not differ significantly from one another. Although there was a pronounced activity deficit on the first block of eight trials, it is possible that this difference emerged across these trials and was not present at the outset. Table 1 shows mean total activity counts for each of the first eight trials. Even on the first trial, the inescapably shocked group was less active than the restrained controls $[\mathrm{t}(14)=2.16, \mathrm{p}<.05]$.

The data indicate that inescapable shock produced an activity deficit in the presence of shock even though fixed tail electrodes, rather than grid shock, were used. This finding supports the idea that the activity deficit reflects a reduction in unconditioned activity

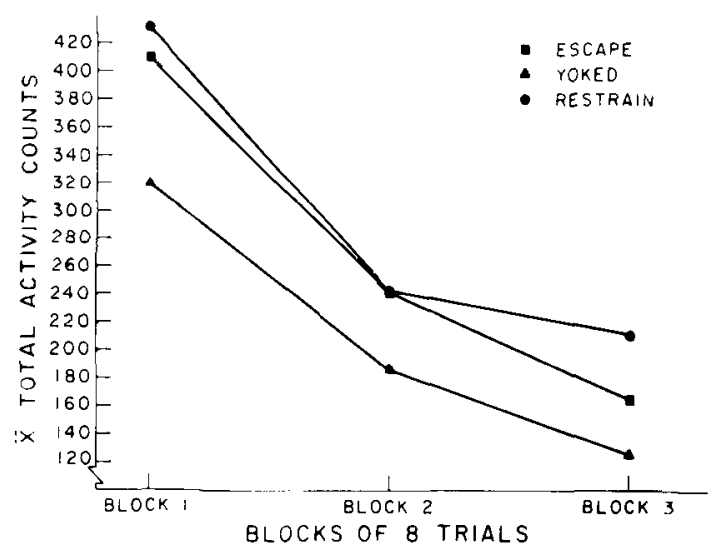

Figure 1. Mean total number of activity counts in the presence of a .6-mA tailshock in an open field, across blocks of eight trials, for escape, yoked, and restrained rats.

to shock and is not produced by learning that reduced movement produces less painful shock. Here, activity reduction could not alter electrical contact, but it occurred nonetheless. Moreover, the activity reduction was present from the very first trial, further reducing the likelihood that learning during the test trials contributes importantly to the deficit. Of course, it is possible that even a greater deficit might exist when the shock is modifiable.

Although these results indicate that the inescapableshock-produced activity deficit does not result from facilitated learning of shock modifiability, they do not decide between the various hypotheses which predict an unconditioned reduction during testing. The explanation proposed by Glazer and Weiss (1976a, 1976b) has been particularly influential. They asserted that the inescapably shocked subjects learn to be inactive in the presence of shock. They claimed that, during the pretreatment phase, the struggling elicited by inescapable shock onset subsides in $3-4 \mathrm{sec}$. Coincidentally, in the typical learned helplessness paradigm, the inescapable shock lasts for $5 \mathrm{sec}$. Even when a triadic design is used, shocks are frequently in the 5-sec range. Thus, cessation of struggling might be accidentally reinforced by shock offset which occurs $1 \mathrm{sec}$ later. Hence, the subject learns a relationship between activity reduction and shock termination and subsequently becomes inactive in the presence of shock in ensuing situations.

Glazer and Weiss (1976a, 1976b) did not measure activity during inescapable shock but merely asserted

Table 1

Mean Total Activity Counts per Trial in Block 1 of Experiment 1

\begin{tabular}{lllllllll}
\hline Group & Trial 1 & Trial 2 & Trial 3 & Trial 4 & Trial 5 & Trial 6 & Trial 7 & Trial 8 \\
\hline Escape & 71.88 & 63.75 & 55.63 & 57.88 & 45.38 & 45.25 & 32.75 & 37.25 \\
Yoked & 61.13 & 52.63 & 46.50 & 38.13 & 30.00 & 31.88 & 28.63 & 31.13 \\
Restrained & 78.38 & 48.88 & 58.25 & 58.00 & 50.38 & 39.63 & 49.25 & 48.50 \\
\hline
\end{tabular}


that it followed the above pattern. Only Anisman et al. (1978) have reported activity measurements within inescapable shocks. However, their inescapable shock was gridshock delivered to freely moving animals. Thus, any within-trial movement reduction would reflect shock mitigation via movement reduction rather than the cessation of unconditioned struggling adventitiously reinforced by shock-intensity reduction. It should be noted that the great majority of learned-helplessness experiments deliver inescapable shock to restrained subjects via fixed tail electrodes. The Glazer and Weiss hypothesis was directed at explaining such experiments, and so within-trial activity changes must be demonstrated in that context. This seemed important to us because casual observation in our laboratory did not reveal the required activity pattern. Experiment 2 represents an attempt to provide the activity measurements required to evaluate the Glazer and Weiss hypothesis.

\section{EXPERIMENT 2}

The purpose of Experiment 2 was to observe the time course of activity during shock presentations using the standard inescapable shock pretreatment used to produce behavioral learned helplessness. This procedure consists of 805 -sec inescapable tailshocks (1.0 mA) delivered on a VI 60-sec schedule. The Glazer and Weiss hypothesis requires that the activity subside after 3-4 sec of shock and that this reduction become more pronounced or occur earlier in the trial as trials progress and reinforcement of the reduction continues.

\section{Method}

Subjects. Eight naive male albino rats, obtained from the Holtzman suppliers, Madison, Wisconsin, and 330-350 $\mathrm{g}$ at the time of testing, served as subjects. They were individually housed and maintained on a 12-h light-dark cycle. Food and water were provided ad lib throughout.

Apparatus. The wheel-turn boxes described in Experiment 1 were modified to accommodate the transmitter and receiver of the motion detector. The sensors were mounted in the top of the box to insure activity counts if the subject was either standing up or lying down and moving.

Procedure. The subjects were placed in the modified wheel-turn boxes, and electrodes were taped to their tails and augmented with electrode paste. The subjects then received the standard learnedhelplessness pretreatment. This consisted of $80 \mathrm{5}$-sec shocks to the tail (1.0 mA) on a VI 60-sec schedule (range of 5-200 sec). Activity during the 5-sec shock periods was recorded for each .5 -sec interval across the 5 -sec shock presentation.

\section{Results and Discussion}

The time course of activity across blocks of 10 trials is shown in Figure 2. As can be seen, there appears to be no cessation of struggling across the .5 -sec shock period. This is true across all eight 10-trial blocks. In each block, the line of best fit through all the points very closely approximates a slope of zero. There also

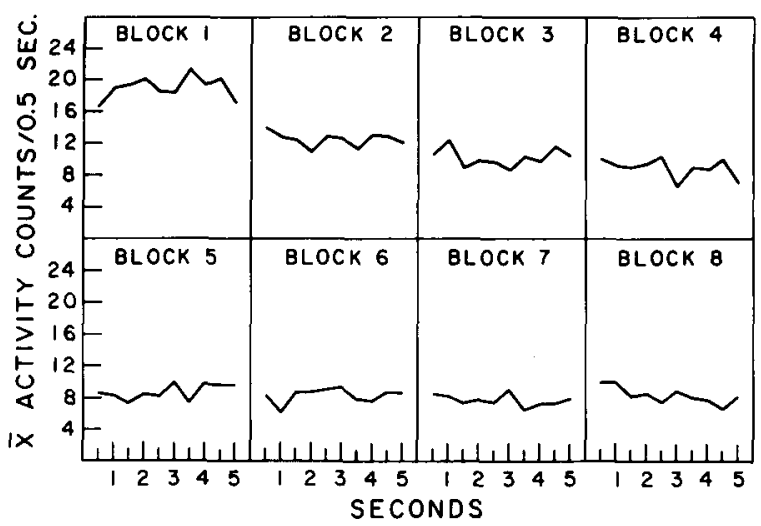

Figure 2. Mean activity counts per .5 sec during 5 -sec shock periods across blocks of $\mathbf{1 0}$ trials for inescapably shocked rats.

appears to be a systematic reduction in activity across trial blocks. These observations were statistically confirmed by a repeated measures analysis of variance. The ANOVA revealed an insignificant effect of activity change within the 5-sec shock periods $[F(9,63)<1.0]$ and a significant effect of activity across blocks of trials $[F(7,49)=22.88, p<.001]$. However, the interaction of the two was insignificant $[F(63,441)<1.0]$. It is possible that grouping trials into 10-trial blocks obscured changes occurring during the first 10 trials. Table 2 shows mean total activity counts for .5-sec intervals for each of the first 10 trials. No within-trial patterns are evident.

There was no change in activity across the 5-sec shock periods. It is unlikely that absence of such an effect can be attributed to an insensitivity of our activity-measuring device. The ultrasonic detectors are quite sensitive to movement, with counts reaching as high as $\mathbf{3 0}$ in a 5-sec shock interval. In addition, a large and systematic reduction in activity across the blocks of trials was measured, thus demonstrating the sensitivity of the system to differences. Finally, the same detector system as in Experiment 1 was used, and differences did emerge.

These findings are inconsistent with the notion that adventitious reinforcement of the cessation of struggling by shock termination is necessary for the production of subsequent activity deficits or shuttlebox escape learning deficits. The inescapable shock procedure used here produces both sorts of deficits, yet activity did not diminish before shock termination and so inactivity or decreased struggling was not present to be reinforced. Furthermore, any such tendency did not become more evident as trials progressed.

However, activity did decrease across trial blocks even though there was no within-trial pattern. Thus, inescapably shocked subjects do struggle less as shocks progress. The absence of within-trial changes, however, rules out an interpretation in terms of the reinforcement of struggling reductions accidentally oc- 
Table 2

Mean Activity Counts per .5-Sec Interval During Shock for Each Trial in Block 1 of Experiment 2

\begin{tabular}{|c|c|c|c|c|c|c|c|c|c|c|}
\hline \multirow[b]{2}{*}{ Trial } & \multicolumn{10}{|c|}{ Seconds } \\
\hline & $0-.5$ & $.5-1.0$ & $1.0-1.5$ & $1.5-2.0$ & $2.0-2.5$ & $2.5-3.0$ & $3.0-3.5$ & $3.5-4.0$ & $4.0-4.5$ & $4.5-5.0$ \\
\hline 1 & 1.47 & 2.13 & 1.63 & 1.56 & 2.41 & 1.30 & 2.53 & 1.70 & 1.75 & 2.45 \\
\hline 2 & 1.88 & 2.75 & 2.88 & 2.88 & 1.88 & 2.38 & 2.00 & 1.75 & 3.38 & 3.00 \\
\hline 3 & 2.00 & 2.13 & 2.50 & 2.25 & 2.38 & 2.50 & 2.75 & 2.50 & 2.88 & 2.25 \\
\hline 4 & 1.75 & 2.50 & 2.25 & 2.00 & 1.63 & 2.63 & 2.50 & 2.50 & 2.38 & 1.88 \\
\hline 5 & 1.38 & 1.61 & 1.47 & 2.58 & 2.07 & 1.67 & 1.89 & 2.38 & 1.78 & 2.14 \\
\hline 6 & 1.72 & 2.38 & 2.00 & 2.56 & 2.16 & 2.30 & 2.03 & 2.08 & 2.13 & 1.45 \\
\hline 7 & 1.63 & 1.50 & 1.63 & 1.50 & 1.13 & 1.63 & 1.75 & 1.75 & 1.38 & 1.63 \\
\hline 8 & 1.50 & 1.25 & 1.88 & 1.63 & 1.50 & 1.88 & 2.75 & 1.75 & 1.88 & 1.75 \\
\hline 9 & 1.75 & 1.13 & 1.63 & 1.75 & 1.38 & 1.13 & 1.63 & 1.38 & 1.88 & 1.38 \\
\hline 10 & 1.50 & 1.63 & 1.50 & 1.38 & 2.00 & 1.00 & 1.38 & 1.50 & 1.13 & 1.25 \\
\hline
\end{tabular}

curring shortly before shock termination, at least using our apparatus and experimental conditions. Unfortunately, the data do not decide between the remaining interpretations. Some other reinforcement mechanism may operate, neurochemical systems involved in the maintenance of movement may be gradually depleted, the incentive to respond may be reduced, analgesia may develop, or any combination of these may occur.

Although the present results make it clear that an activity deficit will occur following exposure to inescapable shock under conditions in which overt adjustments to anticipated shock are unlikely, they do not demonstrate that such adjustments would not occur in circumstances in which they are allowed. Our data imply only that these sorts of changes are not necessary. However, the fact that sizable differences occurred here in a situation in which a shock-mitigating effect of overt postural adjustments was minimized suggests that this sort of behavioral mechanism might typically play only a minor role (Fanselow, 1979; Imada, Yamazaki, \& Morishita, 1981).

In summary, the present experiments support the prior finding that exposure to inescapable shock reduces the level of motor activity in the presence of shock $24 \mathrm{~h}$ later. They go beyond prior data by indicating that this lowered level of activity cannot be explained as a result of contingencies between the aversiveness of shock and movement inherent in the procedures used previously. Fixed body electrodes were employed here so that movement could not alter contact with the electrodes, yet an activity deficit still emerged. Moreover, it was present from the very first test shock and occurred only if the prior shock was inescapable. Thus, it appears that inescapable shock induces changes which lead to an unconditioned activity reduction which does not depend on the presence of a relationship between movement and electrical properties of the aversive stimulus such as the onset and termination of contact, current density, and power. Although such contingencies do exist during gridshock (Wilson \& Butcher, 1980), they are not necessary for the production of behavioral deficits produced by inescapable shock. In addition, the production of the activity deficit does not require a fortuitous relation between the cessation of struggling and shock termination. Such an adventitious relationship did not occur, yet the shock conditions used were sufficient to produce both activity and shuttlebox deficits. Thus, such a mechanism cannot be responsible for learned-helplessness effects.

\section{REFERENCE NOTE}

1. Drugan, R. C., Maier, S. F., \& Misanin, J. R. The impact of inescapable shock on the sensitivity and reactivity to stress in the rat. Paper presented at the meeting of the Rocky Mountain Psychological Association, Denver, 1981.

\section{REFERENCES}

Anderson, D. C., Crowell, C. R., Cunningham, C. L., \& LUPO, J. V. Behavior during shock exposure as a determinant of subsequent interference with shuttlebox escape-avoidance learning in the rat. Journal of Experimental Psychology: Animal Behavior Processes, 1979, 5, 243-257.

Anisman, H., DeCatanzaro, D., \& Remington, G. Escape performance following exposure to inescapable shock: Deficits in motor response maintenance. Journal of Experimental Psychology: Animal Behavior Processes, 1978, 4, 197-218.

Berk, A. M., Marlin, N. A., \& Miller, R. R. Communication: System for delivering tailshock to freely ambulatory rats. Physiology \& Behavior, 1977, 19, 815-818.

Bracewell, R. J., \& Black, A. H. The effects of restraint and noncontingent preshock on subsequent escape learning in the rat. Learning and Motivation, 1974, 5, 53-69.

Campbell, B. A., \& Teghtsoonian, R. Electrical and behavioral effects on different types of shock stimuli on the rat. Journal of Comparative and Physiological Psychology, 1958, 51, 185-192.

F ANSELow, M. S. Naloxone attenuates rat's preference for signaled shock. Physiological Psychology, 1979, 7, 70-74.

Glaze R, H. I., \& WEIss, J. M. Long-term and transitory interference effects. Journal of Experimental Psychology: Animal Behavior Processes, 1976, 2, 191-201. (a)

Glazer, H. I., \& WEISs, J. M. Long-term interference effect: An alternative to "learned helplessness." Journal of Experimental Psychology: Animal Behavior Processes, 1976, 2, 202. 213. (b)

Hollis, K. R., \& Overmier, J. B. Effect of inescapable shock on the efficacy of punishment of appetitive instrumental re- 
sponding by dogs. Psychological Reports, 1973, 33, 903-906. Imada, H., Yamazaki, A., \& Morishita, M. The effects of signal intensity upon conditioned suppression: Effects upon responding during signals and intersignal intervals. Animal Learning \& Behavior, 1981, 9, 269-274.

Jackson, R. L., Maier, S. F., \& Coon, D. J. Long-term analgesic effects of inescapable shock and learned helplessness. Science, 1979, 206, 91-93.

Jackson, R. L., Maier, S. F., \& Rapaport, P. M. Exposure to inescapable shock produces both activity and associative deficits in rats. Learning and Motivation, 1978, 9, 69-98.

Kurtz, K., \& Walters, G. The effects of prior fear exposure on an approach-avoidance conflict. Journal of Comparative and Physiological Psychology, 1962, 55, 1075-1078.

LEvis, D. J. Learned helplessness: A reply and alternative S-R interpretation. Journal of Experimental Psychology: General, 1976, 105, 47-56.

Maier, S. F., \& JACKson, R. L. Learned helplessness: All of us were right (and wrong): Inescapable shock has multiple effects. In G. Bower (Ed.), The psychology of learning and motivation (Vol. 13). New York: Academic Press, 1979.

Maier, S. F., \& Seligman, M. E. P. Learned helplessness: Theory and evidence. Journal of Experimental Psychology: General, 1976, 105, 3-46.
Mowren, O. H., \& Miller, N. E. A multi-purpose learning demonstration apparatus. Journal of Experimental Psychology, $1942,31,163-170$

Muenzinger, K. F., \& W ALz, F. C. An analysis of the electrical stimulus producing a shock. Journal of Comparative Psychology, 1932, 13, 157-171.

O'Connell, B., Chiszar, D., \& Smith, H. M. Effect of poststrike disturbance on strike-induced chemosensory searching in the prairie rattlesnake (Crotalus $V$. viridis). Behavioral and Neural Biology, 1981, 32, 343-349.

Weiss, J. M., Glazer, H. I., \& Pohorecky, L. A. Coping behavior and neurochemical changes: An alternative explanation for the original "learned helplessness"' experiments. In G. Servan \& A. Kling (Eds.), Animal models in human psychobiology. New York: Plenum Press, 1976.

Weiss, J. M., Stone, E. A., \& Harrell, N. Coping behavior and brain norepinephrine in rats. Journal of Comparative and Physiological Psychology, 1970, 72, 153-160.

Wilson, W. J., \& Butcher, L. L. A potential shock-reducing contingency in the backshock technique: Implications for learned helplessness. Animal Learning \& Behavior, 1980, 8, 435-440.

(Manuscript received October 20, 1981; revision accepted for publication March 3, 1982.) 